\title{
ANÁLISE DA INFLUÊNCIA DO CONCRETO NO PROCESSO DE INDUÇÃO A CORROSÃO DO AÇO ZAR 280*
}

\author{
Talita Julha Pereira Andrade ${ }^{1,}$ \\ Lucas Barcelos Dias², \\ Gabriel Burlandy Mota de Melo ${ }^{3}$, \\ Mariana Matos Arantes ${ }^{4}$, \\ Daniele Gomes Carvalho ${ }^{5}$,
}

\section{Resumo}

O Steel Frame é um sistema construtivo eficiente e sustentável. Sua estrutura é em perfis de aço e pode suportar até 4 pavimentos, e sua fundação é em radie. Por isso, os perfis da base são revestidos de manta asfáltica para serem protegidos de agentes degradantes. Após algum tempo, a manta perde sua eficácia, expondo o perfil ao meio. O objetivo dessa pesquisa é explicar a corrosão do perfil, através da investigação por MEV, EDS e teste de tração, mostrando a influência do concreto no mesmo, mediante a determinação de suas características mecânicas após o contato. Os resultados mostram difusão dos elementos do concreto no aço, afetando suas propriedades mecânicas através do aumento de limite de resistencia a tração e redução do módulo de elasticidade. Houve também redução na superfície de zinco, mostrando principio de corrosão.

Palavras-chave: Steel Frame; ZAR 280; Corrosão; Propriedades mecânicas.

\section{ANALYSIS OF THE INFLUENCE OF CONCRETE IN THE PROCESS OF ZAR 280 STEEL INDUCTION CORROSION}

\begin{abstract}
Steel Frame is an efficient and sustainable construction system. It's structure is of steel profiles and can support up to 4 floors, and it's foundation is in slabs. That is why the profiles in the base are coated with an asphalt sheet for protection from degrading agents. After a while, the sheet looses it's effectiveness, exposing the profile to it's surroundings. The objective of this research is to explain the corrosion of the profile, by the investigation by MEV, EDS and traction test, showing the influence of concrete on the steel profile, by the determination of it's mechanical characteristics after contact. The results show diffusion of concrete's elements on the steel, affecting it's mechanical properties by increasing the traction resistance limit and the reduction of the magnitude of elasticity. There was also a reduction of the zinc surface, showing the beginning of corrosion.
\end{abstract}

Keywords: Steel Frame; ZAR 280; Corrosion; Mechanical Properties.

\footnotetext{
1 Graduanda em Engenharia Civil, Acadêmico de Engenharia Civil, UniBRAS/ITPAC Instituto Tocantinense Presidente Antônio Carlos, Araguaína-To

2 Graduando em Engenharia Civil, Acadêmica de Engenharia Civil, UniBRAS/ITPAC Instituto Tocantinense Presidente Antônio Carlos, Araguaína-To

${ }^{3}$ D.C. em Ciências de Materiais, Acadêmico de Pós Doutorado, IME Instituto Militar de Engenharia, Rio de Janeiro-RJ

${ }^{4}$ Esp. Docência do Ensino Superior, Professora Adjunto curso de Engenharia Civil, UniBRAS/ITPAC Instituto Tocantinense Presidente Antônio Carlos, Araguaína-To

${ }^{5}$ D.C. em Ciências de Materiais, Professora Adjunto curso de Engenharia Civil, UniBRAS/ITPAC Instituto Tocantinense Presidente Antônio Carlos, Araguaína-To
} 


\section{INTRODUÇÃO}

O uso intensivo de recursos naturais não recicláveis na engenharia civil, levou a busca de novos materiais, renováveis, e novos métodos de aplicação destes, na engenharia. Nesse cenário, o Steel frame amplia o uso do aço na construção civil, otimizando custo e benefício.

Esse sistema construtivo é composto em sua estrutura de paneis autoportantes de perfis de aço baixa liga, sendo preferencialmente o ZAR 280, parafusados entre si, e na fundação de laje tipo radie, com manta asfáltica entre a laje e os perfis guia com placas de fechamento de OSB e cimentícia, além de manta termoacústica e acabamento sobre gesso acartonado [1][2][3].

O uso de aço baixa liga apresenta diversas vantagens devido à suas propriedades físicas e mecânicas, sendo relativamente mais leves que outras classes de aço e possuir fácil conformação, além de um amplo campo de aplicação por conta dos altos limites de resistência ao escoamento e à ruptura. Entre suas características destacam-se o uso de elementos de liga e o baixo teor de carbono, sendo este abaixo de 0,30\% [3][4][5][6].

O aço baixa liga ZAR 280 (Zincado de alta resistência), com produção e desempenho de acordo as normas ABNT NBR 10735:1989 [7], NBR 15253: 2014 [8], NBR 14762: 2010 [9] e NBR 6355: 2003 [10], é o representante da classe aplicado ao Steel Frame, onde são exploradas suas características no desempenho estrutural da edificação. Sua composição é determinada por carbono $(0,20 \%)$, fósforo (0,10\%) e Enxofre (0,04\%), e apresenta limite de escoamento de $280 \mathrm{MPa}$ e limite de ruptura de $380 \mathrm{MPa}$.

Apesar de suas vantagens, um problema inerente ao aço baixa liga é a sua deterioração, que como todas as classes de aço submetidas ao meio externo, está suscetível a corrosão metálica.

A corrosão de uma liga ou material metálico acontece por uma ação não intencional química ou eletroquímica, que gera transformação da sua composição, a partir das superfícies expostas a ambientes e elementos agressivos, comprometendo seu desempenho [11].

Em relação ao ZAR 280 e suas desvantagens, é necessário analisar o ponto de vista da corrosão, uma vez que a manta asfáltica aplicada entre o perfil e a laje radier, que o protege tem tempo de ação limitado e isso pode determinar o seu desempenho e durabilidade.

O intuito dessa pesquisa é compreender o comportamento mecânico do aço baixa liga ZAR 280 em um meio agressivo exposto a corrosão, sendo esse o concreto com resistência de $10 \mathrm{MPa}$, para orientar seu uso em outras formas na construção civil além da aplicação no sistema construtivo Steel Frame, podendo colaborar com aspectos econômicos e ambientais.

\section{MATERIAIS E MÉTODOS}

\section{1- Preparação dos corpos de prova e confecção do concreto}

Para a confecção do concreto foi utilizado o Cimento Portland (CP II E - 32) Tocantins, Areia Grossa comercial e brita 1 de diâmetro nominal igual a 19. O aço utilizado para análise de corrosão foi o baixa liga ZAR 280 , de espessura $0,90 \mathrm{~mm}$.

Os parâmetros utilizados para a resistência característica do concreto à compressão (fck) de $10 \mathrm{MPa}$ na execução, ensaios prévios necessários e calculo da 
dosagem, foram seguidos através do método $\mathrm{ACl}$ 211.1-91S e das normas para agregados NBR - 7211: 2009 [12], NBR NM 26: 2009 [13], NBR NM 45: 2006 [14], NBR NM 53: 2009 [15], NBR - 9775: 2011 [16], BR NM 52: 2009 [17], NBR NM 248: 2003 [18].

O traço executado do concreto para 10 MPa é 1:3,85:2,7:0,77 (Cimento, Agregado Miúdo, Agregado Graúdo e Fator água/cimento) respectivamente.

O corte das chapas foi feito com o o uso de lixadeira no padrão ASTM E8M 16a [19] para chapas de fina espessura.

Depois da confecção na betoneira, o concreto foi despejado em moldes de corpo de prova cilíndrico de $20 \mathrm{~cm}$ de altura por 10 de diâmetro. $O$ adensamento foi feito conforme as normas descritas acima, e em seguida foram inseridas as chapas de aço. Posteriormente os corpos de prova concreto-aço foram colocados em processo de cura. A cura das primeiras 24 horas, foi feita ao ar livre para finalização total da pega do concreto, e em seguida ocorreu o desforme dos corpos cilíndricos, e imersão destes no tanque de água para cura úmida [20]. As idades de cura escolhidas para a pesquisa foram de 14 e 21 dias.

\subsection{Caracterização}

O ensaio de tração foi realizado seguindo a norma NBR ISO 6892-1:2013 [21] para chapas finas, com uso do equipamento INSTRON EMIC 23-200, com células de carga de 2000 N. Foram submetidos ao teste, 20 corpos de prova retirados do concreto, com 14 e 21 dias de cura.

A análise estatística do erro associado, foi relalizada com o uso de desvio padrão populacional, já que este mostra a medida do grau de dispersão dos valores em relação ao valor médio, para a amostra representada por toda a população, dada pela equação (Equação 1),onde $x$ representa a média das amostras, $\bar{x}$ representa uma amostra e $n$ representa o número de amostras avaliadas [22].

$$
D_{p}=\sqrt{\frac{\sum(x-\bar{x})^{2}}{n}}
$$

Os parâmetros de Tensão e alongamento percentual, foram obtidos através do gráfico resultante do teste de tração, e o módulo de elasticidade ou módulo de Young,foi obtido através da Lei de young dada pela equação (Equação 2), onde $\sigma$ é a tensão proporcional para $\varepsilon$ que é a deformação que para aços é de até $0,2 \%$ e $E$ é o módulo de elasticidade do material.

$$
E=\frac{\sigma}{\varepsilon}
$$

A análise da camada zincada afetada foi realizada através da microscopia eletrêtrica de varredura (MEV) com acoplamento de energy dispersive sistem (EDS), com o uso do microscópio JEOL JSM-5800 IV com as seguintes condições analíticas: feixe de elétrons com resolução nominal de $0,0035 \mu \mathrm{m}$, regulável para tensões de 5 a $30 \mathrm{kV}$; vácuo da análise de alto vácuo, tempo de contagem do EDS 100s por análise. O mapa químico para as amostras foram obtido pela contagem de raios $X$ característicos durante $1 \mathrm{~h}$. O programa de análise do mapa químico usado foi o SEM AFORE. 


\section{RESULTADOS E DISCUSSÃO}

Os resultados do teste de tração forneceram quatro parâmetros de propriedades mecânicas inerentes ao aço baixa liga apresentados na tabela 1 e nas figuras 1, 2, 3 e 4, são estes: tensão de escoamento, limite de resistência a tração (LRT), módulo de elasticidade e alongamento \%.

Tabela 1. Valores das propriedades mecânicas do teste de tração

\begin{tabular}{ccccc}
\hline $\begin{array}{c}\text { Corpo de } \\
\text { prova }\end{array}$ & $\begin{array}{c}\text { Tensão de } \\
\text { Escoamento } \\
(\mathrm{MPa})\end{array}$ & $\begin{array}{c}\text { Módulo de } \\
\text { Elasticidade } \\
(\mathrm{GPa})\end{array}$ & $\begin{array}{c}\text { Limite de } \\
\text { Resistência a } \\
\text { Tração }(\mathrm{MPa})\end{array}$ & $\begin{array}{c}\text { Alongamento } \\
\text { Percentual } \\
(\%)\end{array}$ \\
\hline Matriz & $277,83 \pm 15,62$ & $138,91 \pm 7,81$ & $323,20 \pm 10,20$ & $18,23 \pm 8,13$ \\
\hline 14 dias & $294,05 \pm 17,48$ & $98,51 \pm 6,95$ & $341,62 \pm 18,47$ & $15,3 \pm 1,67$ \\
\hline 21 dias & $316,31 \pm 14,33$ & $91,76 \pm 5,78$ & $360,35 \pm 9,00$ & $17,28 \pm 0,97$ \\
\hline
\end{tabular}

O primeiro parâmetro analisado, foi o comportamento das propriedades mecânicas para os corpos de prova matriz, 14 dias e 21 dias.

É possivel observar tanto na tabela 1 quanto nas figura $1,2,3$ e 4 que as propriedades da matriz encontram-se em conformidade com a norma, o que era esperado, uma vez que a amostra foi testada a partir do parâmetro comercial.

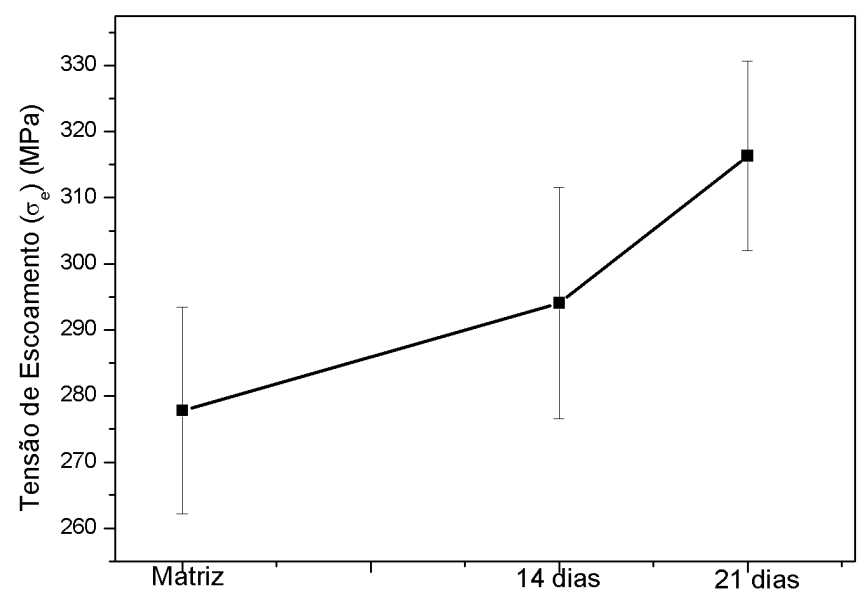

Figura 1. Tensão de escoamento dos corpos de prova de ZAR 280.

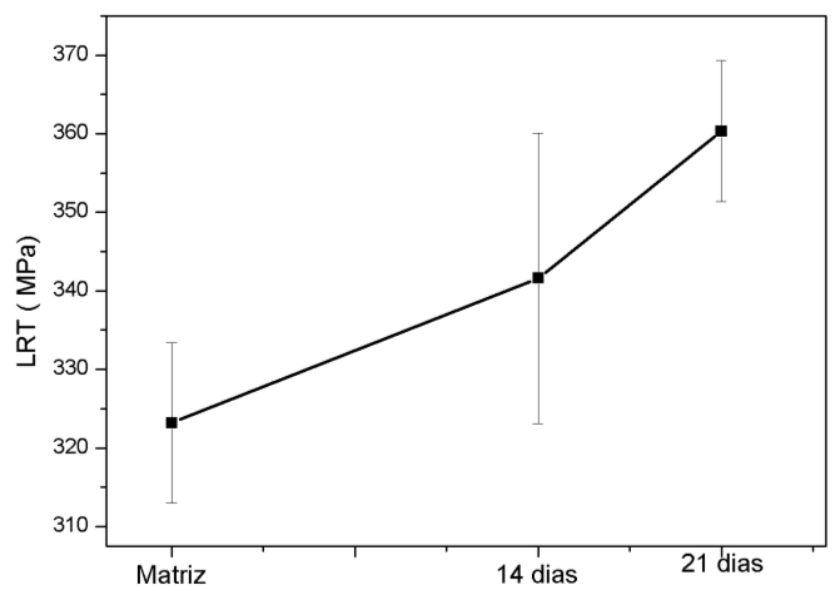

Figura 2. Limite de resistência a tração dos corpos de prova de ZAR 280. 
Quando compara-se a chapa de aço matriz com os corpos de prova de aço submetidos a 14 e 21 dias de cura do concreto, através da figura 1, é possivel observar um aumento total de $14,3 \%$ na tensão de escoamento. O mesmo comportamento é notado na figura 2, onde o limite de resistência a tração (LRT), eleva-se em $11,2 \%$ considerando-se o tempo final de 21 dias.

Na figura 3 no entanto, há um declínio expressivo de 34,5\% para o módulo de elasticidade, quando relaciona-se a matriz aos outros corpos de prova. Para o alongamento percentual figura 4 constata-se uma redução não tão expressiva. Esta, fica em torno de $5,5 \%$.

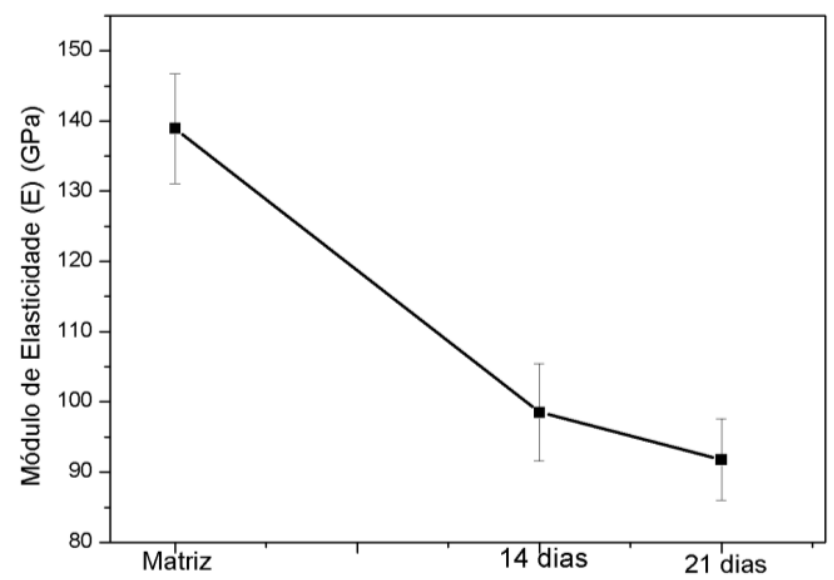

Figura 3. Módulo de elasticidade dos corpos de prova do ZAR 280.

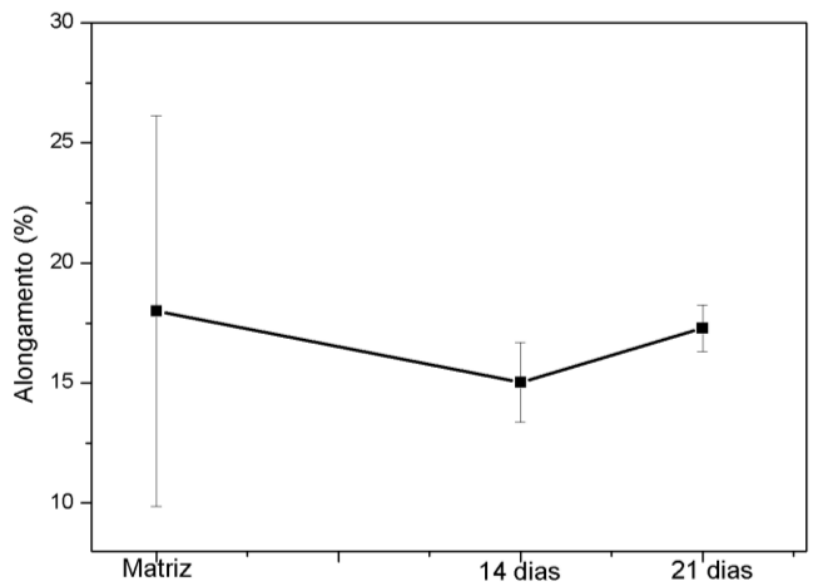

Figura 4. Alongamento percentual dos corpos de prova do ZAR 280.

Estes resultados corroboram com os aferidos nas Figuras 1 e 2, pois o há o acressimo de LRT juntamente com a tensão de escoamento, inversamente proporcional ao declíneo do módulo de eslasticidade e do alongamento \%, que demonstram uma fragilização do material, e esta tem relação direta com a influência do concreto no perfil.

Os resultados do MEV-EDS forneceram de forma qualitativa e quantitativa a avaliação da camada zincada que reveste este perfil, sendo esta degradada pelo concreto.

Das figuras 5 a 10, constata-se que as micrografias e os espectros de EDS, apresentam as superfícies dos corpos de prova e os elementos presentes nos mesmos. Na tabela 2, pode-se observar os elementos provindos do mapa químico para a matriz, 14 dias e 21 dias, comparados com os elementos oriundos do concreto. 


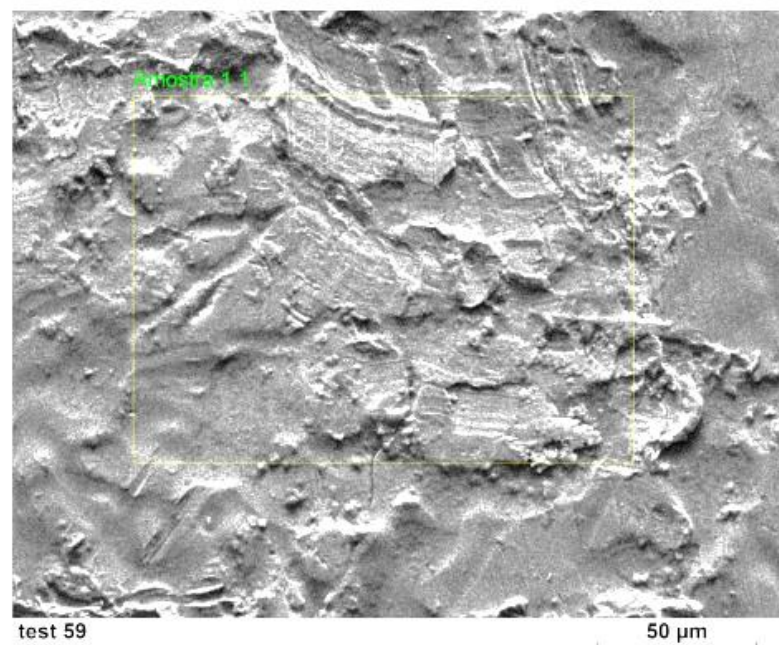

SE MAG: $500 \times \mathrm{HV}: 20.0 \mathrm{kV}$ WD: $9.6 \mathrm{~mm}$ Px: $0.30 \mu \mathrm{m}$

Figura 5. Micrografia matriz.

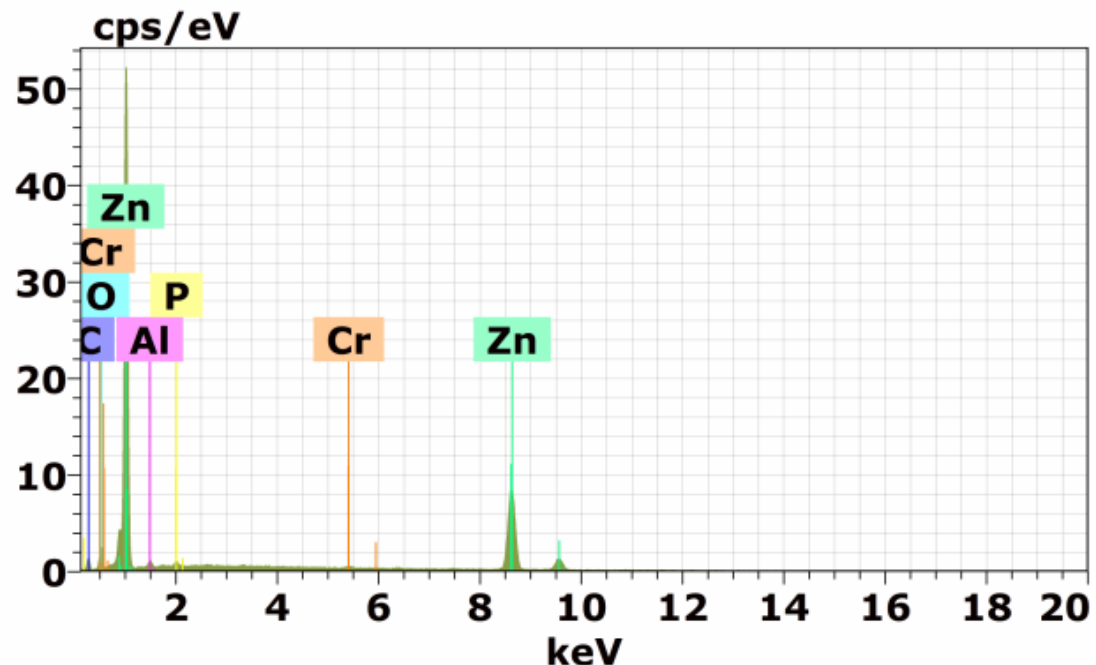

Figura 6. Espectro de EDS matriz.

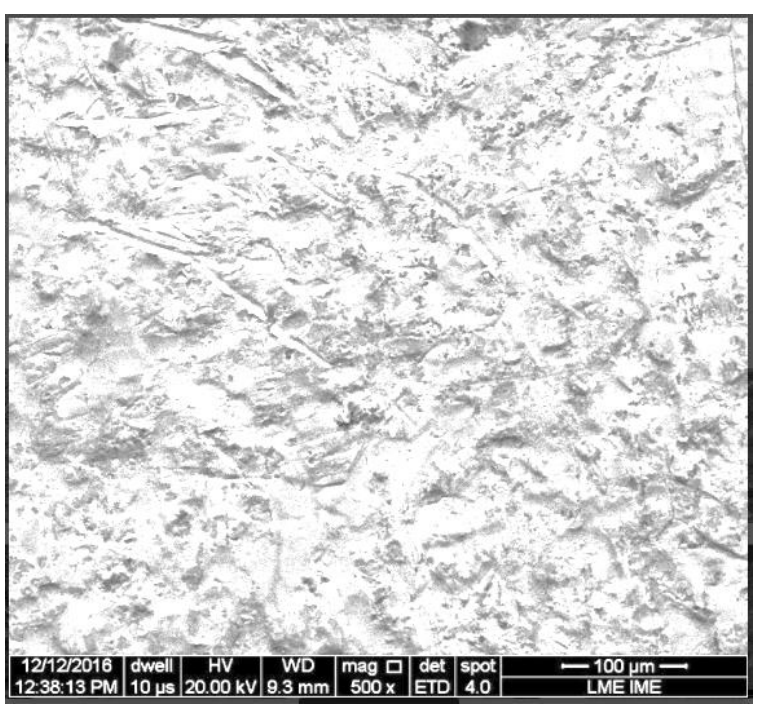

Figura 7. Micrografia 14 dias 


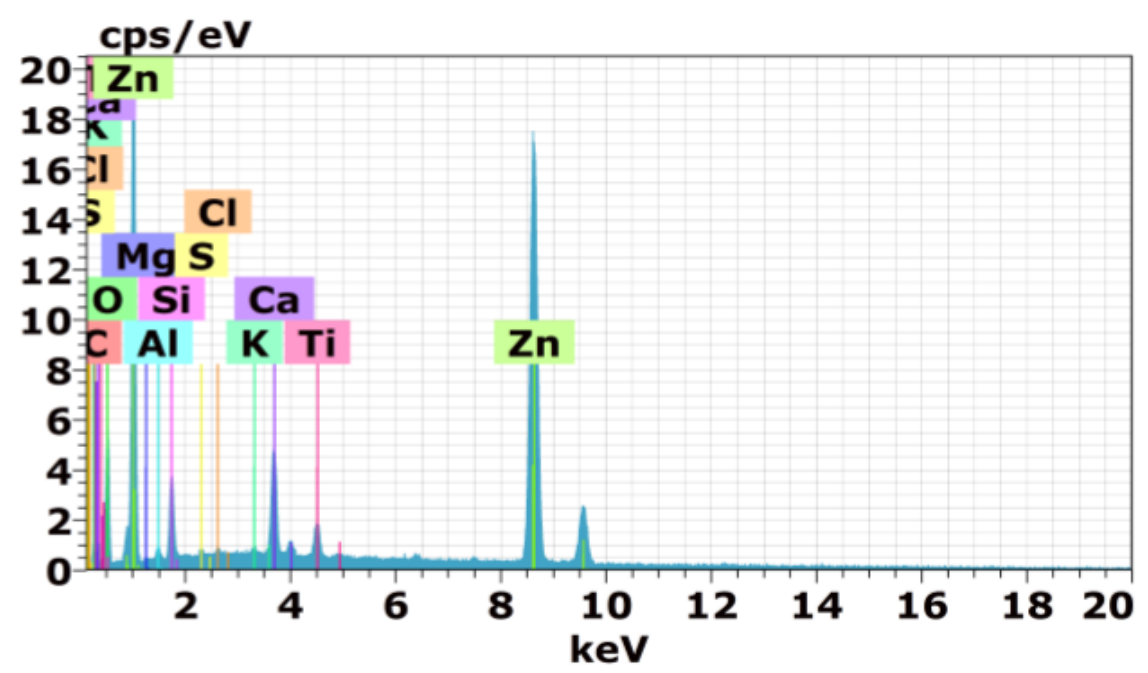

Figura 8. Espectro de EDS 14 dias

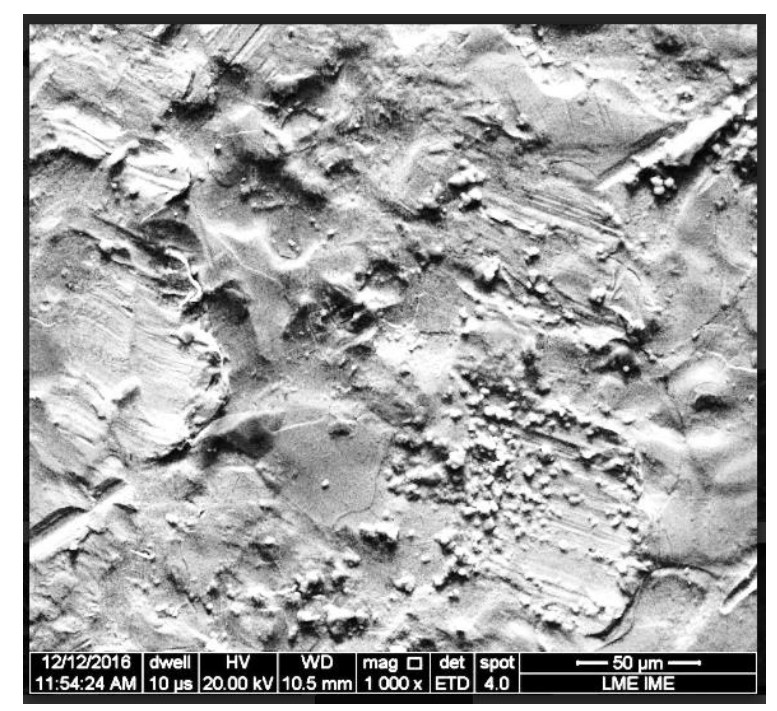

Figura 9. Micrografia 21 dias

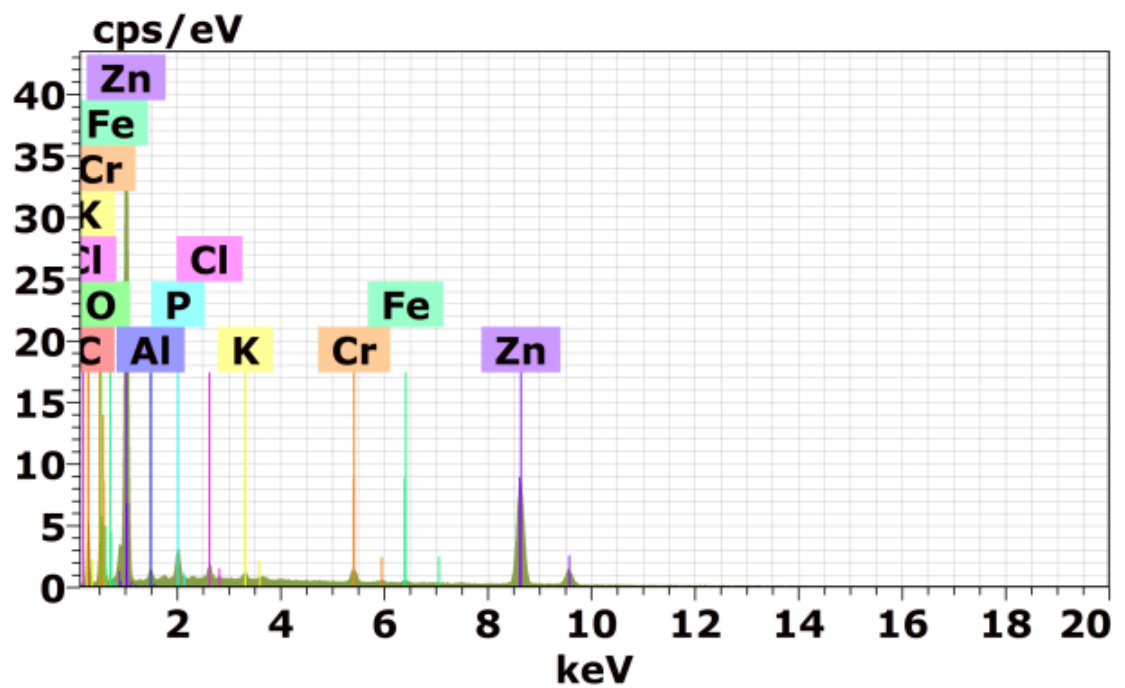

Figura 10. Espectro de EDS 21 dias 
Tabela 2. Elementos presentes na amostra de ZAR 280

\begin{tabular}{ccccccc}
\hline \multicolumn{2}{c}{ Matriz } & \multicolumn{2}{c}{ 14 dias } & \multicolumn{2}{c}{21 dias } & Concreto \\
\hline Elementos & $\%$ presente & Elementos & $\%$ presente & Elementos & $\%$ presente & Elementos \\
\hline $\mathrm{C}$ & 0,2 & $\mathrm{Al}$ & 0,33 & $\mathrm{Al}$ & 0,11 & $\mathrm{Cl}$ \\
\hline $\mathrm{P}$ & 0,1 & $\mathrm{~K}$ & 0,11 & $\mathrm{~K}$ & 0,15 & $\mathrm{~K}$ \\
\hline $\mathrm{S}$ & 0,04 & $\mathrm{Si}$ & 1,46 & $\mathrm{Cl}$ & 0,35 & $\mathrm{Si}$ \\
\hline $\mathrm{Fe}$ & 99,75 & $\mathrm{Ca}$ & 2,47 & $\mathrm{C}$ & 0,2 & $\mathrm{Ca}$ \\
\hline $\mathrm{Zn}$ & 90 & $\mathrm{Cl}$ & 0,08 & $\mathrm{Zn}$ & 58,84 & $\mathrm{~S}$ \\
\hline $\mathrm{Al}$ & 0,15 & $\mathrm{Mg}$ & 1 & $\mathrm{P}$ & 1,07 & \\
\hline & $\mathrm{C}$ & 0,2 & & & \\
\hline & $\mathrm{S}$ & 0,13 & & & \\
\hline
\end{tabular}

A presença de $\mathrm{K}, \mathrm{Al}, \mathrm{Si}, \mathrm{Ca}$ e $\mathrm{S}$ podem ser explicadas através da composição do concreto e seus agregados escolhidos para este trabalho. Outros elementos no entanto, como o Ti e Cr provém de uma possivel contaminação do processo de corte das amostras. O aparecimento de Al na matriz, pode ser entendido como elemento indesejável no processo de zincagem da industria.

Sabendo-se que as reações de hidratação do concreto são maiores num período inicial de até 14 dias, e que a maior temperatura do calor de hidratação do cimento ocorre também nas primeiras idades de cura [23], é possivel explicar por este fator o acressimo de elementos existentes na amostra de 14 dias e um ausencia na de 21.

Logo, estes resultados fornecem embasamento para explicar a fragilização encontrada nas propriedades mescânicas, pois, a difusão dos elementos do concreto no corpo de prova do ZAR 280, elevou a capacidade de carga do aço quando disposto em esforços de tração, reduzindo sua elasticidade e alongamento percentual.

$\mathrm{Na}$ figura 11, é visto que a camada de zinco sofre significante redução de aproximadamente $35,5 \%$ sendo que o principal produto que se forma nessa camada oxidada é o $\mathrm{ZnO}$. Este efeito pode ser entendido como o inicio do processo de corrosão do perfil metálico de aço ZAR 280, já que sua camada proptetora estaria sendo sacrificada.

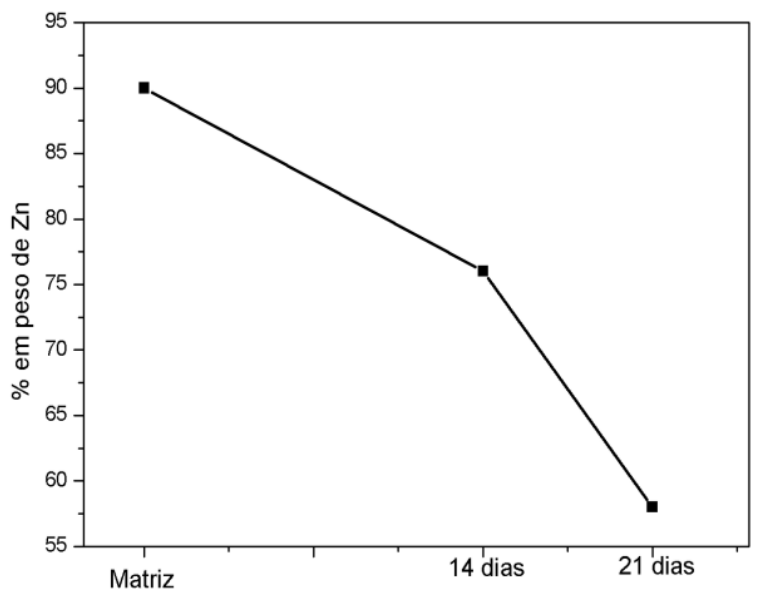




\section{CONCLUSÃO}

Figura 11. \% em peso de Zn para os corpos de prova

Com os resultados analisados, pode-se mostrar nas propriedades mecânicas e químicas do ZAR 280, como ocorre a influencia do concreto de fck $10 \mathrm{MPa}$. Constatou-se também influencia na camada de zinco que desempenha proteção contra corrosão.

Para as propriedades do aço, comprovou-se modificação expressiva na capacida de resistência a tensões, mas em contra parte, houve redução da elasticidade do mesmo, aumentando a rigidez e podendo torna-lo frágil.

Com a análise de EDS, foi possivel observar a inclusão de elementos adivindos do concreto no aço, o que corrobora com o enrijecimento do material demonstrado pelo teste de tração.

Esses aspectos, levam a concluir que consequentemente, com a perda da camada externa de zinco, o aço fica exposto e inicia a sua corrosão, além de permitir maior difusão de elementos externos para seu interior, afetando o desempenho estrutural do Steel frame.

\section{Agradecimentos}

Ao Centro universitário Norte Brasil UniBRAS/ITPAC pelo apoio e uso dos laboratórios, ao Programa de Iniciação Científica da IES, aos técnicos dos laboratórios de engenharia e ao Instituto Militar de Engenharia, pela realização da microscopia eletrônica de varredura.

\section{REFERÊNCIAS}

[1] Kokke AS, Sarmanho AM, Crasto RCM. Stell Framing Arquitetura. Rio de Janeiro. Instituto Aço Brasil/ Centro Brasileiro da Construção em Aço, 2012.

[2] SINAT. Sistema construtivo a seco Saint-Gobain - Light Steel Frame. Brasília.2015.

[3] AllenE. Fundamentals of building construction - Materials and Methods, $3^{\circ}$ ed., John Wiley \& Sons Inc., 1999.

[4] Dias LAM. Estruturas de Aço, conceitos tecnicas e linguagem, Zigurate, 2001

[5] Chiaverini V. Tecnologia Mecânica, Estrutura e Propriedades das Ligas Metálicas, Vol. 1. São Paulo. McGraw - Hill, 1914.

[6] Callister WDJR. Ciência Engenharia de Materiais, Uma Introdução. Rio de Janeiro. LTC. 2012.

[7] ABNT. NBR 10735 Chapas de aço de alta resistência mecânica zincadas continuamente por imersão a quente - Especificação. RJ, 1989

[8] ABNT. NBR 15253 Perfis de aço formados a frio, com revestimento metálico, para painéis estruturais reticulados em edificações - Requisitos gerais. RJ, 2014.

[9] ABNT. NBR 14762 Dimensionamento de estruturas de aço constituídas por perfis formados a frio. RJ, 2010. 
[10] ABNT. NBR 6355 Perfis estruturais de aços formados a frio- Padronização. RJ, 2003.

[11] Bauer FLA. Materiais de construção Vol. 2, 5e ed. Rio de Janeiro, LTC, 2011.

[12] ABNT. NBR 7211 Agregados para concreto - Espeficicação. RJ, 2009

[13] ABNT. NBR NM 26 Agregados - Amostragem. RJ, 2009

[14] ABNT. NBR NM 45 Agregados - Determinação da massa unitária e do volume de vazios. RJ, 2006

[15] ABNT. NBR NM 53 Agregado graúdo - Determinação da massa específica, massa específica aparente e absorção de água. RJ, 2009

[16] ABNT. NBR 9775 Agregado miúdo - Determinação do teor de umidade superficial por meio do frasco de Chapman - Método de ensaio. RJ, 2011

[17] ABNT. NBR NM 52 Agregado miúdo - Determinação da massa específica e massa específica aparente. RJ, 2009

[18] ABNT. NBR NM 248 Agregados - Determinação da composição granulométrica. RJ, 2003

[19] ASTM E8M - 16a Standard Test Methods for Tension Testing of Metallic Materials. USA, 2010.

[20] ABNT. NBR 5738-3. Concreto - Procedimento para moldagem e cura de corpos de prova.- Parte 3: Aços estruturais, RJ, 2012.

[21] ABNT NBR ISO 6892-1 Materiais metálicos - Ensaio de Tração. Parte 1: Método de ensaio à temperatura ambiente. RJ, 2013

[22] Montgomery CD, Runger CG, Estatística Aplicada e Probabilidade para Engenheiros, 4ํㅡㄹ., LTC, 2005.

[23] Neville AM. Propriedades do concreto. São Paulo. Bookman. 2016

[0] ABNT. NBR 7008-3. Chapas e bobinas de aço revestidas com zinco ou liga zinco-ferro pelo processo contínuo de imersão a quente.- Parte 3: Aços estruturais, ABNT, RJ, 2012. 